\title{
IMPROVEMENTS IN VALVE RELIABILITY DUE TO IMPLEMENTATION OF EFFECTIVE CONDITION MONITORING PROGRAMS
}

\author{
Stan Hale \\ CRANE NUCLEAR, Inc.
}

\begin{abstract}
Modern diagnostic systems for motor-operated valves, pneumatic control valves and checkvalves have facilitated a shift in the maintenance philosophy for valves and actuators in nuclear power plants from schedule based to condition-based maintenance (CBM). This shift enables plant management to focus resources and schedule priority on the plant equipment that warrants attention thereby not wasting resources or increasing the human factors risk on equipment that has not degraded. The most recent initiatives combine condition monitoring with risk/safety insights to focus attention and resources on the right equipment at the right time consistent with each component's safety-significance.

The activities of the ASME working groups responsible for nuclear O\&M codes have kept pace with the technology and process improvements necessary to maximize the technical and economic benefits of condition based and risk informed maintenance. This paper discusses adoption of valve condition monitoring in the nuclear power industry, changes to ASME codes and standards during the 90's to facilitate adoption of condition monitoring technology for in-service testing and recent efforts to combine risk insights with condition monitoring strategies to achieve the highest level of valve reliability and nuclear safety without over inflating maintenance cost.
\end{abstract}

